\title{
Contrast sources for the infrared images taken by the Venus mission AKATSUKI
}

\author{
Seiko Takagi and Naomoto Iwagami \\ Department of Earth and Planetary Science, University of Tokyo, Bunkyo-ku, Tokyo 113-0033, Japan
}

(Received September 18, 2010; Revised December 24, 2010; Accepted January 24, 2011; Online published June 21, 2011)

\begin{abstract}
A feasibility study has been carried out to look for the source of contrast that will be seen in the infrared images of Venus taken by the cameras on board AKATSUKI. This procedure used a cloud model based on the measurements of previous entry probes and radiative transfer calculations. The source of the small contrast expected in the $0.90-\mu \mathrm{m}$ dayside image was found to be due to inhomogeneity in the cloud optical thickness, with the variations in cloud altitude and temperature having little effect. The source of the large contrast expected in the 2.26- $\mu \mathrm{m}$ nightside image was also found to be due to inhomogeneity in the cloud optical thickness. We attempted to determine the representative altitude of the cloud layers, but this could not be specified to one particular layer. The brightness expected in the $2.02-\mu \mathrm{m}$ dayside image was found to be affected by the cloud altitude, as expected since the 2.02- $\mu \mathrm{m}$ is in a moderate $\mathrm{CO}_{2}$ absorption band; however, it is also affected by the cloud optical thickness. The brightness expected in the $10-\mu \mathrm{m}$ image was found to be affected mostly by temperature; however, the effects due to cloud optical thickness and cloud altitude are also important. It is necessary to use all of the information obtained at various wavelengths to gain a correct understanding of the brightness distribution of the Venus images taken by AKATSUKI.
\end{abstract}

Key words: Contrast sources, infrared image, cloud optical thickness, cloud layer, Venus, AKATSUKI.

\section{Introduction}

The superrotation of Venus atmosphere is one of the most remarkable and mysterious phenomena in the solar system. Although several theories on its generation have been proposed (e.g., Gierasch, 1975), to date, the exact mechanism has not been identified. The main aim of the Japanese mission AKATSUKI is to elucidate this mechanism, and to this end, five cameras and a radio occultation instrument are on board. Since each camera uses different wavelengths, they are able to observe targets at various altitudes at the same time. The strategy of the AKATSUKI mission is to understand the acceleration mechanism by measuring various meteorological parameters in the acceleration region using cloud tracking and radio occultation techniques at various altitudes. The AKATSUKI mission and the instruments on board have been described in detail by Nakamura et al. (2007). Here, we discuss the contrast sources for the $0.90 \pm 0.005-\mu \mathrm{m}$ dayside image of the $1-\mu \mathrm{m}$ camera (IR 1 ), the $2.26 \pm 0.03-\mu \mathrm{m}$ nightside image and the $2.02 \pm 0.02-\mu \mathrm{m}$ dayside image of the $2-\mu \mathrm{m}$ camera (IR2), the $10 \pm 2-\mu \mathrm{m}$ image of the $10-\mu \mathrm{m}$ camera (LIR) and their representative altitudes.

Figure 1(a) shows a $0.986-\mu \mathrm{m}$ dayside image of Venus taken by solid state imaging (SSI) of the Galileo spacecraft (obtained from the NASA website). Although it appears almost flat, there are some small-scale (approx. $300 \mathrm{~km}$ )

Copyright (C) The Society of Geomagnetism and Earth, Planetary and Space Sciences (SGEPSS); The Seismological Society of Japan; The Volcanological Society of Japan; The Geodetic Society of Japan; The Japanese Society for Planetary Sciences; TERRAPUB.

doi:10.5047/eps.2011.01.007 features with a contrast of 3\% (Belton et al., 1991). Such a faint feature in the $0.90-\mu \mathrm{m}$ image taken by the IR $1 \mathrm{cam}-$ era must be tracked to determine the meteorological parameters. Consequently, accurate information on the contrast source and of the representative altitude is important. The same may be applicable to the 2.02- $\mu \mathrm{m}$ dayside, $2.26-\mu \mathrm{m}$ nightside and the $10-\mu \mathrm{m}$ day- and nightside images. The $10-\mu \mathrm{m}$ day- and nightside images resemble each other because the scattered sun light is much weaker than the thermal emission in this wavelength region. Figure 1(b) shows a 2.3- $\mu \mathrm{m}$ nightside image of Venus taken by near-infrared mapping spectrometer (NIMS) of Galileo (obtained from the NASA website). There are a lot of features showing a contrast of almost $100 \%$ (Tsang et al., 2009). It is also interesting to investigate whether the source of such a large contrast in the nightside image seen in Fig. 1(b) is consistent with the source of small contrast seen in the dayside image in Fig. 1(a). In this study, the contrast is defined as (maximum brightness-minimum brightness)/mean brightness.

\section{Simulation}

A Venus atmosphere model, molecular line databases, a cloud model, and a radiative transfer calculation are necessary to calculate the brightness distribution on the Venus disk.

\subsection{Cloud model}

A mean cloud model and deviations from the mean were calculated from the measured data collected by previous entry probes, such as the Soviet Veneras series. Figure 2(ag) represents the optical thickness of the upper, middle, and lower clouds measured by the Pioneer Venus large probe 
(a)

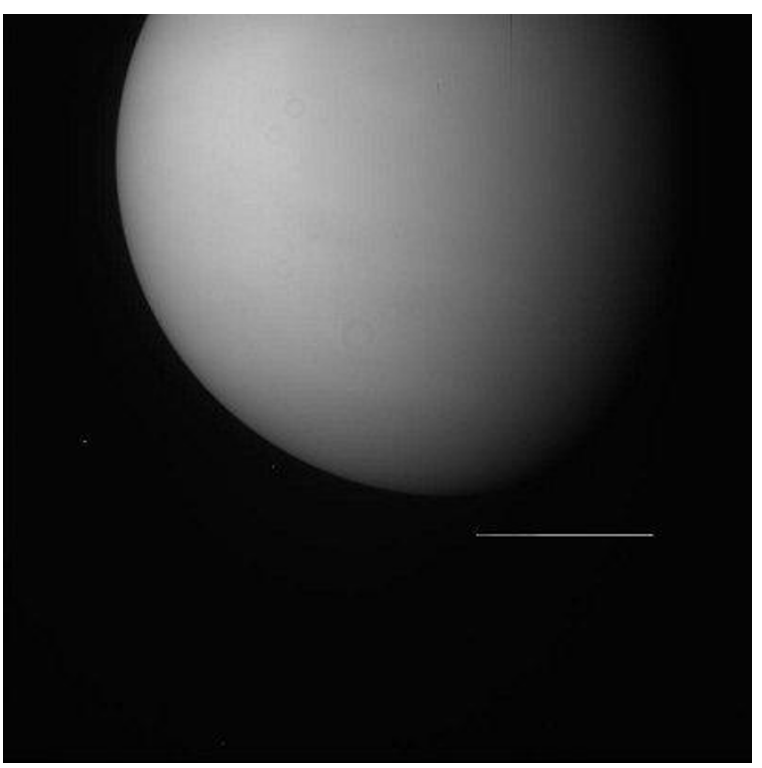

(b)

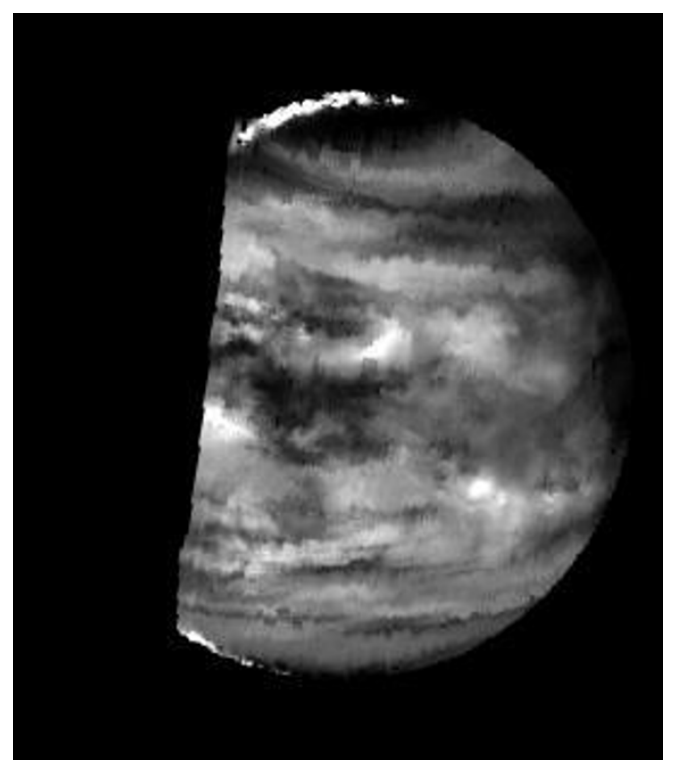

Fig. 1. (a) A $0.986-\mu \mathrm{m}$ image of Venus dayside taken by SSI on board Galileo (from the NASA website). (b) A 2.3- $\mu$ m nightside image of Venus taken by the NIMS on board Galileo (from the NASA website).

and Veneras 9-14 as summarized in table IVa of James et al. (1997). The mean of seven profiles (Fig. 2(a-g)) is shown in Fig. 2(h). To calculate the mean, we ignore the difference in the measuring wavelengths $(630 \mathrm{~nm}$ for Pioneer Venus and $920 \mathrm{~nm}$ for Veneras; the difference in the optical thickness at these wavelengths is only a few tenths of percent or less, being much smaller than the variance seen in Fig. 2(a-g). An upper haze layer with a total thickness of unity is added to the mean cloud model (see Table 1) following table II of Crisp (1986).

The optical thickness of each cloud layer shown in Fig. 2(h) is distributed to three particle modes (mode1, 2, and 3 ) and shown in Table 1. The ratios among each particle mode are taken from table 5 of Knollenberg and Hunten (1980). The maximum negative and the maximum positive deviations of the seven profiles shown in Fig. 2(a-g) from the mean (Fig. 2(h)) are also shown in Table 1. In order to use this mean cloud model in the radiative transfer calculation using 50 layers of 2-km-thick, the optical thickness of each mean cloud layer in Table 1 is redistributed to the 2-km-thick layers so as to keep a constant mixing ratio of cloud particles within each (middle, upper and upper haze) layer. Data on the modified cloud model is given in Table 2 and the model is illustrated in Fig. 3. The scale heights within each cloud layer, as determined from VIRA 1985 (Keating et al., 1985), for the middle and upper cloud layers and upper haze layers are 8.3, 6.0, 5.1 (bottom upper haze $70-80 \mathrm{~km}$ ), and $4.3 \mathrm{~km}$ (top upper haze $80-90 \mathrm{~km}$ ), respectively. In this redistribution, the total cloud optical thickness of each layer is kept as shown in Table 1. The lower cloud layer is modified to have an altitude region of $48-50 \mathrm{~km}$ instead of $47.5-50 \mathrm{~km}$. At $57 \mathrm{~km}$ (the boundary altitude between the upper and middle cloud layers), the optical thicknesses due to the upper and middle layers are combined and set in the 56- to 58-km layer.

\subsection{Radiative transfer calculation}

Synthetic spectra were calculated by means of line-byline method using the HITRAN 2004 molecular database (Rothman et al., 2005) and the $\mathrm{CO}_{2}$ HITEMP database (Wattson and Rothman, 1992; Pollack et al., 1993), the VIRA1985 model atmosphere (Keating et al., 1985), and a solar line atlas (Livingston and Wallace, 1991). The subLorentz line shape is applied for $\mathrm{CO}_{2}$ in the same way as in Pollack et al. (1993), and the Voigt line shape (Humlicek, 1992) is applied for the other gases. Scattering by the cloud particles is taken into account by using a plane-parallel radiative transfer code RSTAR (Nakajima and Tanaka, 1986) modified for the Venus atmosphere (G. L. Hashimoto, private communication) with the cloud model noted in the previous section (Table 2, Fig. 3). Cloud parameters of three modes, namely, 1, 2, and 3, are calculated by assuming a $75 \% \mathrm{H}_{2} \mathrm{SO}_{4}$ solution for the particles based on the Mie theory (e.g., Crisp, 1986). In the RSTAR code, the refractive index of $\mathrm{H}_{2} \mathrm{SO}_{4}$ is taken from WCP-55 (1983).

\section{Results}

3.1 Source of the contrast in the $0.90-\mu \mathrm{m}$ image

Venus dayside spectra in the $0.90-\mu \mathrm{m}$ region are calculated with various total cloud optical thicknesses. Figure $4(\mathrm{a}-\mathrm{d})$ show examples of calculated brightness $B_{\lambda}$ and the transmission of filters $T_{\lambda}(0.90-\mu \mathrm{m}$ dayside, $2.02-$ $\mu \mathrm{m}$ dayside, $2.26-\mu \mathrm{m}$ nightside, and $10-\mu \mathrm{m}$ day and nightside, respectively). The $0.90-\mu \mathrm{m}$ region is located in an atmospheric window. The integrated brightness $I$ may be calculated as

$$
I=\int T_{\lambda} B_{\lambda} d \lambda
$$

where $\lambda$ is wavelength, and the integration is carried out within the passband of the filter. Figure 5 shows integrated brightness $I$ as a function of the entire cloud optical thickness. A $50 \%$ increase in the optical thickness is found to 

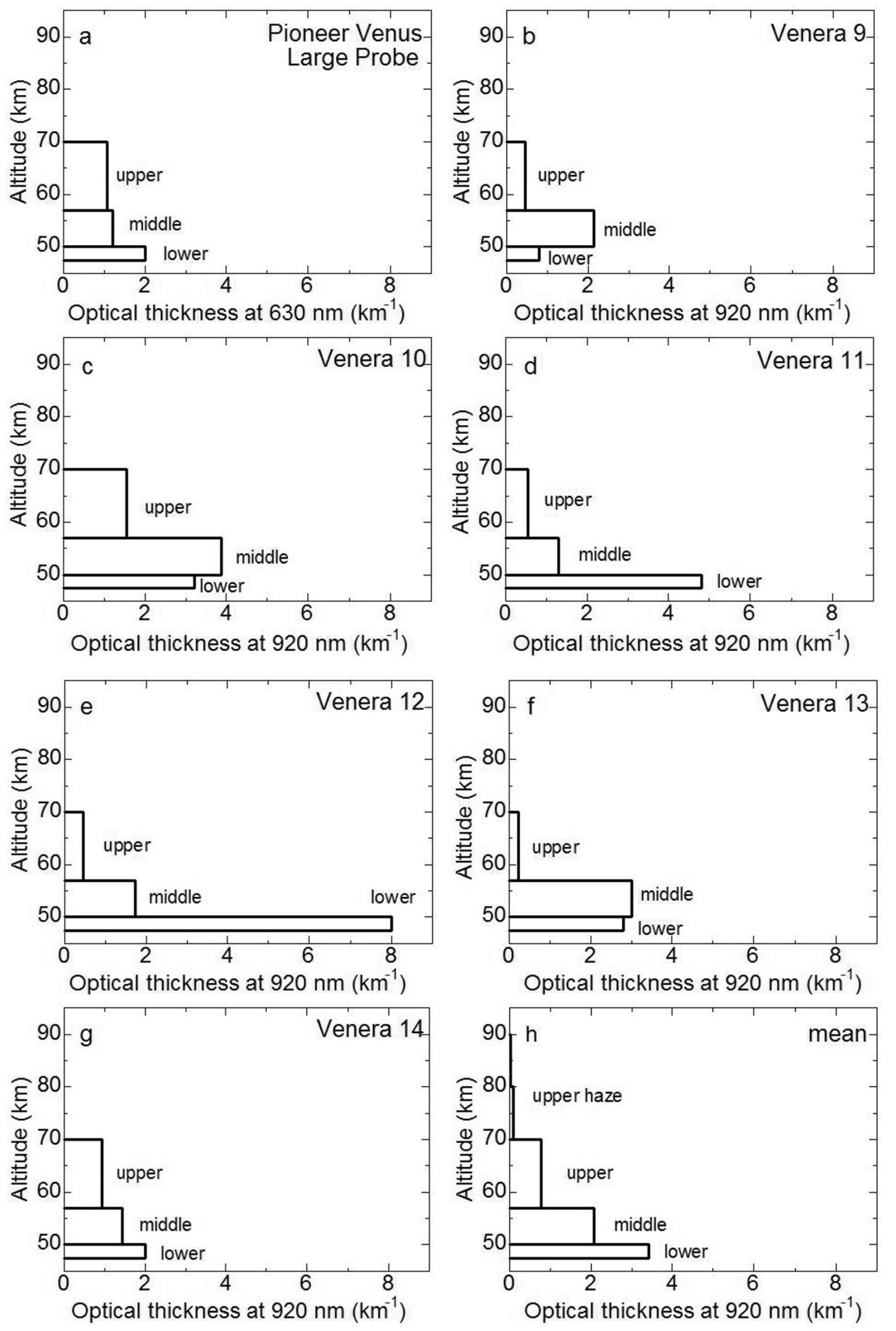

Fig. 2. Optical thickness of three cloud layers measured by the entry probes summarized by James et al. (1997). (a) Pioneer Venus Large Probe; (b-g) Veneras 9-14; (h): mean of seven profiles $(\mathrm{a}-\mathrm{g})$. The upper haze layer is added to the mean following Crisp (1986). 
Table 1. Mean optical thickness of cloud layers at $920 \mathrm{~nm}$ based mainly on Venera entry probe data summarized by James et al. (1997). Upper haze layers based on Pioneer Venus data (Crisp, 1986) are added. The ratios among the particle modes are from Knollenberg and Hunten (1980). The maximum positive and negative deviations are also determined from the same data set; however, those for the upper haze layers are just assumed to be $50 \%$.

\begin{tabular}{|c|c|c|c|c|c|c|}
\hline & \multicolumn{4}{|c|}{ Optical thickness } & \multirow{2}{*}{$\begin{array}{c}\text { Maximum } \\
\text { negative deviation }\end{array}$} & \multirow{2}{*}{$\begin{array}{c}\text { Maximum } \\
\text { positive deviation }\end{array}$} \\
\hline & Mode1 & Mode2 & Mode 3 & Total & & \\
\hline Upper haze $(80-90 \mathrm{~km})$ & 0.200 & 0.0 & 0.0 & 0.2 & $-50 \%$ & $+50 \%$ \\
\hline Upper haze (70-80 km) & 0.14 & 0.66 & 0.0 & 0.8 & $-50 \%$ & $+50 \%$ \\
\hline Upper $(57-70 \mathrm{~km})$ & 2.941 & 7.059 & 0.0 & 10.0 & $-70 \%$ & $+100 \%$ \\
\hline Middle (50-57 km) & 0.490 & 5.096 & 8.915 & 14.5 & $-42 \%$ & $+86 \%$ \\
\hline Lower $(47.5-50 \mathrm{~km})$ & 0.334 & 1.268 & 6.898 & 8.5 & $-76 \%$ & $+135 \%$ \\
\hline
\end{tabular}

Table 2. The cloud model used in this study for calculating radiative transfer. Optical thickness of each mode in each layer ( $2 \mathrm{~km}$ thick) at $920 \mathrm{~nm}$ is represented.

\begin{tabular}{|c|c|c|c|c|}
\hline \multirow[t]{2}{*}{ Layer center altitude (km) } & \multicolumn{4}{|c|}{ Optical thickness per $2 \mathrm{~km}$} \\
\hline & Mode1 & Mode2 & Mode3 & Total \\
\hline 89 & 0.013 & 0.0 & 0.0 & 0.013 \\
\hline 87 & 0.020 & 0.0 & 0.0 & 0.020 \\
\hline 85 & 0.033 & 0.0 & 0.0 & 0.033 \\
\hline 83 & 0.052 & 0.0 & 0.0 & 0.052 \\
\hline 81 & 0.082 & 0.0 & 0.0 & 0.082 \\
\hline 79 & 0.011 & 0.052 & 0.0 & 0.063 \\
\hline 77 & 0.015 & 0.077 & 0.0 & 0.093 \\
\hline 75 & 0.024 & 0.114 & 0.0 & 0.138 \\
\hline 73 & 0.036 & 0.168 & 0.0 & 0.204 \\
\hline 71 & 0.053 & 0.249 & 0.0 & 0.302 \\
\hline 69 & 0.149 & 0.355 & 0.0 & 0.504 \\
\hline 67 & 0.208 & 0.495 & 0.0 & 0.703 \\
\hline 65 & 0.290 & 0.691 & 0.0 & 0.981 \\
\hline 63 & 0.405 & 0.946 & 0.0 & 1.369 \\
\hline 61 & 0.565 & 1.346 & 0.0 & 1.911 \\
\hline 59 & 0.789 & 1.878 & 0.0 & 2.667 \\
\hline 57 & 0.596 & 1.777 & 0.819 & 3.192 \\
\hline 55 & 0.114 & 1.186 & 2.084 & 3.384 \\
\hline 53 & 0.146 & 1.509 & 2.652 & 4.307 \\
\hline 51 & 0.186 & 1.920 & 3.374 & 5.480 \\
\hline 49 & 0.334 & 1.268 & 6.898 & 8.500 \\
\hline
\end{tabular}

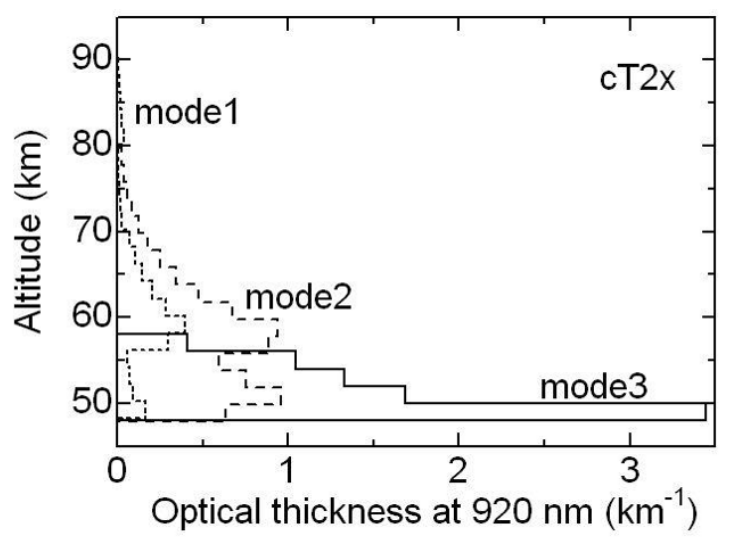

Fig. 3. The cloud model used for the calculation reported here made from the mean profile shown in Fig. 2(h) by adjusting it to a thickness of $2 \mathrm{~km}$ and to a constant mixing ratio of particles in each layer; mode1 (short dashed line), mode2 (long dashed line), mode3 (solid line). cause a $4.1 \%$ increase in brightness, while a $50 \%$ decrease causes a $8.7 \%$ decrease in brightness. As seen in Fig. 2(a$\mathrm{g})$, this amount of variation in the optical thickness is actually present. A similar procedure was performed with various cloud altitudes; however, this procedure reveals that brightness changes only $\pm 0.2 \%$ when the cloud altitudes changes by $\pm 4 \mathrm{~km}$. Since the $0.90-\mu \mathrm{m}$ region is in a window for $\mathrm{CO}_{2}$ absorption, variation of the $\mathrm{CO}_{2}$ column abundance above the cloud does not greatly affect the calculated brightness. This variation of $\pm 4 \mathrm{~km}$ in the Venus cloud altitude may actually be present (see, for example, Iwagami et al., 2008; Ignatiev et al., 2009). A similar procedure is performed by changing the atmospheric temperature, which reveals that changes in temperature scarcely even affect brightness: a $\pm 10 \mathrm{~K}$ increase in temperature causes only a $\pm 0.02 \%$ change in brightness. This is due to the dependence of the absorption line intensity on temperature. It may be concluded that the source of the contrast of the order of $3 \%$ expected in the $0.90-\mu \mathrm{m}$ image is due to 

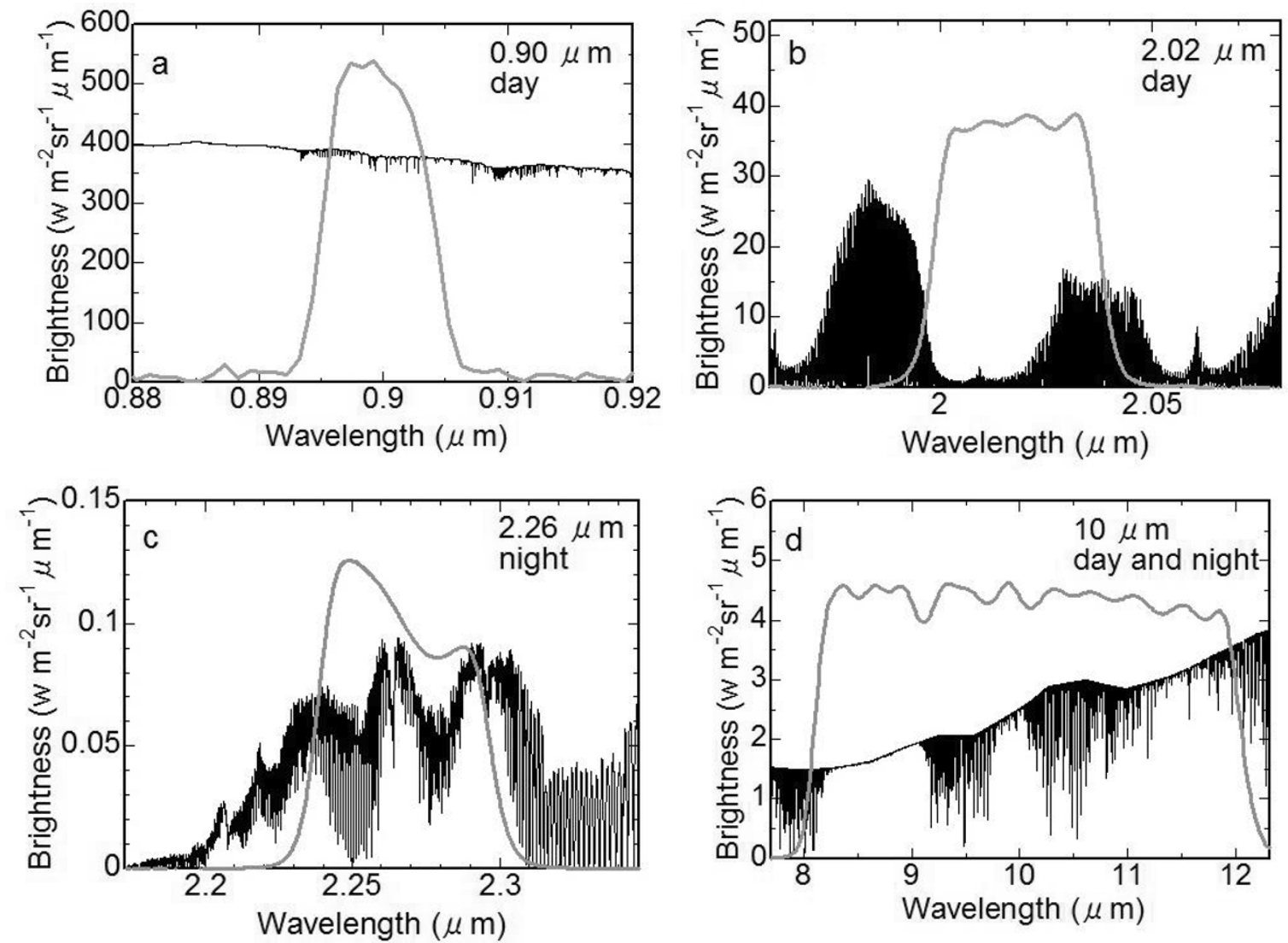

Fig. 4. Examples of calculated brightness (thin solid curve) and the transmission profiles of the filter (thick solid curve); (a) $0.90-\mu$ m dayside, (b) 2.02- $\mu \mathrm{m}$ dayside, (c) 2.26- $\mu \mathrm{m}$ nightside, (d) $10-\mu \mathrm{m}$ dayside and nightside. The maximum transmissions of the filters are $0.27,7.77,84.1$, and $92.6 \%$ for $0.90,2.02,2.26$, and $10-\mu \mathrm{m}$, respectively.

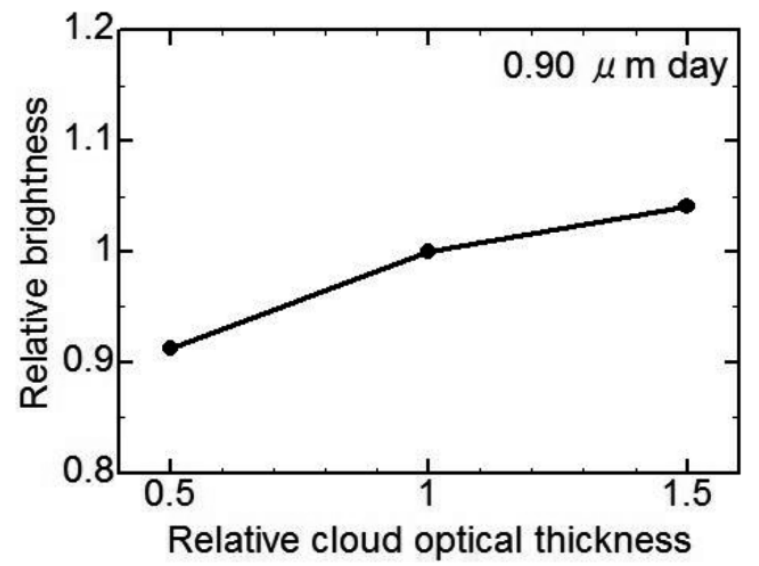

Fig. 5. Calculated and normalized $0.90-\mu \mathrm{m}$ integrated brightness as a function of the normalized total cloud optical thickness (total thickness of 34.0 as a reference).

variation in the cloud optical thickness.

3.2 Source of the contrast in the $2.26-\mu \mathrm{m}$ nightside image

The Venus nightside brightness at around $2.26-\mu \mathrm{m}$ is calculated as the thermal emission of the atmosphere and the surface after scattering by the cloud. The brightness variation with the various total cloud optical thickness is shown in Fig. 6. A 50\% increase in the optical thickness is found to cause an $88 \%$ decrease in brightness, and a

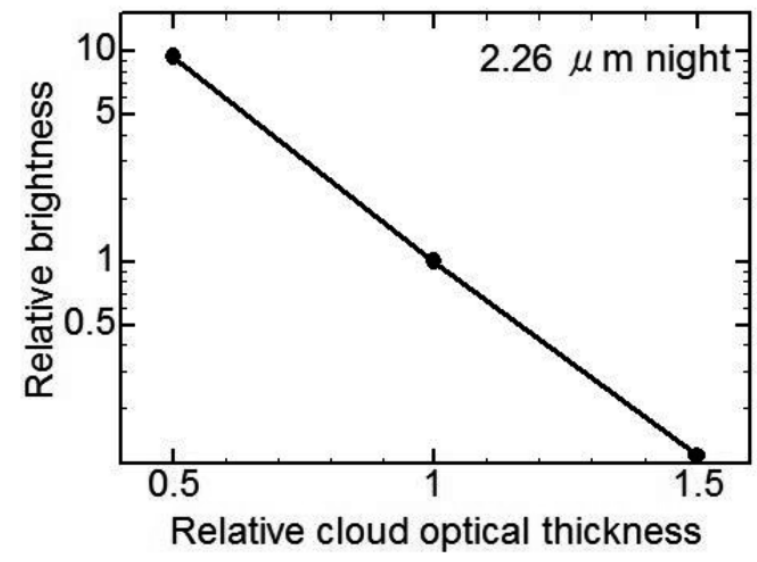

Fig. 6. Calculated and normalized 2.26- $\mu \mathrm{m}$ nightside brightness as a function of the normalized total cloud thickness.

$50 \%$ decrease causes an $830 \%$ increase in brightness. In comparison, the responses due to changes in cloud altitude and temperature are much less: the brightness changes from +11.6 to $-1.5 \%$ when the cloud altitude deviation changes from $-4 \mathrm{~km}$ to $+4 \mathrm{~km}$, and it changes from -22 to $+27 \%$ when the cloud temperature deviation changes from $-10 \mathrm{~K}$ to $+10 \mathrm{~K}$. The source of the $100 \%$ contrast expected to be seen in the $2.26-\mu \mathrm{m}$ image is therefore found to be mostly due to variation in the cloud optical thickness. 
Table 3. Maximum contrast expected for the $0.90-\mu \mathrm{m}$ dayside and 2.26- $\mu \mathrm{m}$ nightside images calculated for the maximum positive and negative deviations in each layer shown in Table 1.

\begin{tabular}{lcc}
\hline & $\begin{array}{c}\text { Maximum contrast } \\
\text { at } 0.90-\mu \mathrm{m}(\%)\end{array}$ & $\begin{array}{c}\text { Maximum contrast } \\
\text { at 2.26- } \mu \mathrm{m}(\%)\end{array}$ \\
\hline Upper haze $(70-90 \mathrm{~km})$ & 1.0 & 7 \\
Upper $(57-70 \mathrm{~km})$ & 5.8 & 117 \\
Middle $(50-57 \mathrm{~km})$ & 5.5 & 255 \\
Lower $(48-50 \mathrm{~km})$ & 4.3 & 289 \\
\hline
\end{tabular}

\subsection{Representative altitude for the $0.90-\mu \mathrm{m}$ dayside contrast and the $2.26-\mu \mathrm{m}$ nightside contrast}

The source of the small contrast expected to be seen in the $0.90-\mu \mathrm{m}$ dayside image and the large contrast in the 2.26 $\mu \mathrm{m}$ nightside image are both found to be due to variation in the cloud optical thickness. To determine their representative altitudes, the integrated brightness in the $0.90-\mu \mathrm{m}$ and $2.26-\mu \mathrm{m}$ regions are calculated with various sets of optical thickness of layers. The brightness corresponding to the maximum negative deviation and the maximum positive deviation, respectively, at each cloud layer is calculated layer by layer. That is, the responses in brightness are calculated by changing the optical thickness of one region (e.g., middle cloud layer only). The difference between the responses is defined as contrast and is represented in Table 3. For example, in the case of a lower cloud layer with an optical thickness of 8.5 in the mean cloud model, a $135 \%$ increase in optical thickness $(8.5 \times 2.35=20.0)$ is found to cause a $2.4 \%$ increase in brightness, while a $76 \%$ decrease in the optical thickness $(8.5 \times 0.24=2.04)$ is found to cause a $1.9 \%$ decrease in brightness; therefore, the maximum contrast expected for the $0.90-\mu \mathrm{m}$ image is $4.3 \%(=2.4+1.9 \%)$.

As seen in Table 3, all layers, with the exception of the upper haze layer, have the potential to cause a contrast of $\geq 3 \%$ in the $0.90-\mu \mathrm{m}$ dayside image. The data in Table 3 also show that all cloud layers, again with the exception of the upper haze layer, may cause a contrast of $\geq 100 \%$ in the 2.26- $\mu \mathrm{m}$ image.

\subsection{The contrast source for the $2.02-\mu \mathrm{m}$ dayside image and the $10-\mu \mathrm{m}$ image}

Similar procedures to those performed for the $0.90-\mu \mathrm{m}$ and 2.26- $\mu \mathrm{m}$ calculations in Section 3.1 were also performed for the $2.02-\mu \mathrm{m}$ dayside image and the $10-\mu \mathrm{m} \mathrm{im}$ age. The result of the $2.02-\mu \mathrm{m}$ calculation is shown in Fig. 7. The brightness changes $\pm 50 \%$ when the cloud optical thickness changes $\pm 50 \%$ (in the case of no deviation in the cloud altitude). The brightness changes from -60 to $+109 \%$ when the cloud altitude deviation changes from -4 to $+4 \mathrm{~km}$ (in the case of the reference optical thickness). This considerable response to cloud altitude is due to the fact that the 2.02- $\mu \mathrm{m}$ region is not located in an atmospheric window but in a $\mathrm{CO}_{2}$ absorption band (see Fig. 4(b)). A $\pm 10 \mathrm{~K}$ change in the temperature causes only a $\pm 0.0035 \%$ change in brightness. In summary, the contrast in the 2.02$\mu \mathrm{m}$ image is found to come from changes in both cloud altitude and cloud optical thickness.

The result for the $10-\mu \mathrm{m}$ image is shown in Fig. 8. The brightness changes from +37 to $-16 \%$ when the cloud optical thickness changes from -50 to $+50 \%$ (in the case of no

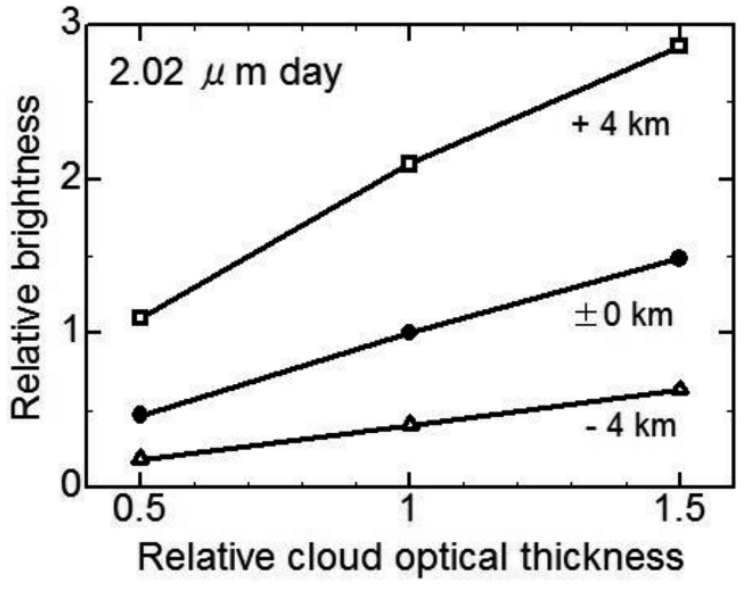

Fig. 7. Calculated and normalized $2.02-\mu \mathrm{m}$ dayside brightness as a function of the normalized total cloud optical thickness and cloud altitude deviation.

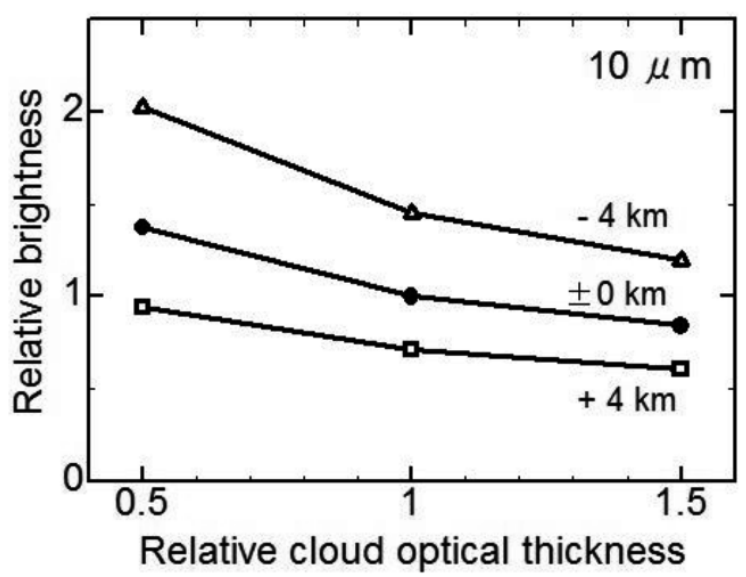

Fig. 8. Calculated and normalized $10-\mu \mathrm{m}$ brightness as a function of the normalized total cloud optical thickness and cloud altitude deviation.

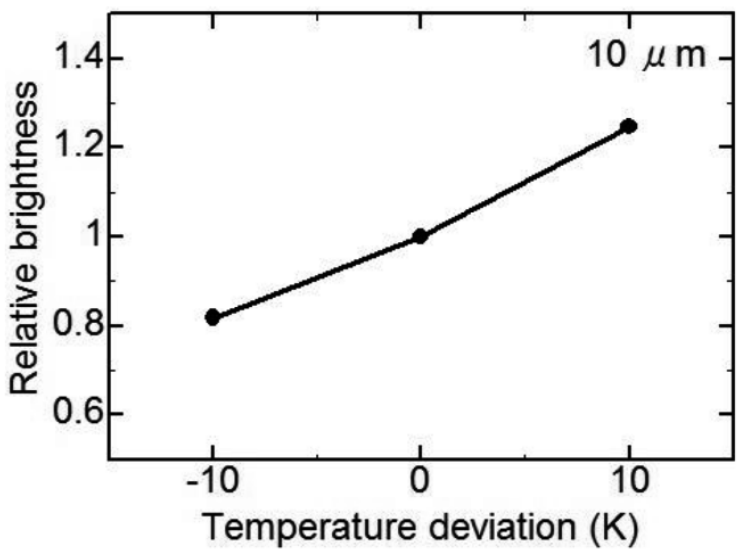

Fig. 9. Calculated and normalized $10-\mu \mathrm{m}$ brightness as a function of cloud temperature deviation.

deviation in cloud altitude). The brightness changes from +45 to $-29 \%$ when the cloud altitude deviation changes from -4 to $+4 \mathrm{~km}$ (in the case of the reference optical thickness). Such a change with the deviation in altitude is due to the fact that the $10-\mu \mathrm{m}$ region is not located in an at- 
mospheric window but in a moderate $\mathrm{CO}_{2}$ absorption band (see Fig. 4(d)). As shown in Fig. 9, a $\pm 10 \mathrm{~K}$ change in temperature causes a $\pm 20 \%$ change in brightness. In the case of the $10-\mu \mathrm{m}$ image, the contrast is due not only to temperature change but also to changes in both cloud optical thickness and cloud altitude deviation.

\section{Discussion}

Belton et al. (1991) reported that the contrast source in the $0.986-\mu \mathrm{m}$ dayside image taken by SSI on board Galileo is located in the bottom of the middle cloud layer. These authors base their conclusion on the fact that the violet tracers show larger zonal wind velocities $\left(101 \mathrm{~m} \mathrm{~s}^{-1}\right)$ than those of the near-infrared tracers $\left(78 \mathrm{~m} \mathrm{~s}^{-1}\right)$. By using the average vertical wind shear (approx. $1.5 \mathrm{~m} \mathrm{~s}^{-1} \mathrm{~km}^{-1}$ ) estimated from the previous entry probes, such as Veneras (figure 9 of Schubert, 1983), they conclude that the violet and near-infrared contrast sources are separated by $15 \mathrm{~km}$ in the vertical direction. Since the representative altitude of the violet image is $70 \mathrm{~km}$ (Kawabata et al., 1980), the $0.986-\mu \mathrm{m}$ dayside representative altitude should be $55 \mathrm{~km}$. However, the results of the our study show a possibility that the source may be located in any of the cloud regions (48$70 \mathrm{~km})$.

Carlson et al. (1991) reported that the contrast source of the $2.3-\mu \mathrm{m}$ nightside image is located at $50 \mathrm{~km}$. These authors based their conclusion on data obtained by the Galileo NIMS. According to their discussion, the contrast found in the 2.3- $\mu \mathrm{m}$ image (20:1) requires a tenfold change in cloud optical thickness at $2.3 \mu \mathrm{m}$. However, the brightness temperature deviation at $3.71 \mu \mathrm{m}$ exceeds the observed value of $0.13 \mathrm{~K}$ if such large change does actually occur in the upper or middle cloud layer. They concluded that only a change in the lower cloud layer at around $50 \mathrm{~km}$ may satisfy both conditions. However, our results show a possibility that the contrast source may also be located in the middle or upper cloud region.

The 2.02- $\mu \mathrm{m}$ brightness is found to provide information on both cloud altitude and cloud optical thickness. The 10$\mu \mathrm{m}$ brightness is found to give information on temperature, cloud optical thickness, and cloud altitude. In order to separate such cloud parameters one by one, it seems necessary to introduce information obtained at other wavelength regions. The cloud altitude deviation is determined from $2.02-\mu \mathrm{m}$ brightness by using information on cloud optical thickness from the $0.90-\mu \mathrm{m}$ dayside image; the temperature information may be determined from the $10-\mu \mathrm{m}$ brightness by using the cloud optical thickness and the altitude information obtained from the $0.90-\mu \mathrm{m}$ and the $2.02-\mu \mathrm{m}$ regions.

The error associated with this procedure may be estimated as follows only if the random error of $0.3 \%$ in the $0.90-\mu \mathrm{m}$ dayside image is important. The error in brightness of the $0.90-\mu \mathrm{m}$ dayside image is expected to be $0.3 \%$ (Iwagami et al., in press), which is statistical noise due to fluctuations in photon number. This error corresponds to about unity in the optical thickness in the $0.90-\mu \mathrm{m}$ image according to Fig. 5. Since the reference value of the total cloud optical thickness is 34 , as noted in Table 2, such uncertainties of unity in cloud optical thickness may be converted into an error of $0.03 \mathrm{~km}$ in the cloud altitude devi- ation according to Fig. 7. The error in temperature by the $10-\mu \mathrm{m}$ data is estimated to be $0.09 \mathrm{~K}$ by using the above uncertainties and information shown in Figs. 8 and 9.

It should be noted that the above discussion is the simplest and the most optimistic estimation of errors. The estimate given here means that the error caused by the random noise in the $0.90-\mu \mathrm{m}$ image is negligible. If possible, we should take into account all uncertainties, such as instrumental errors (calibration errors, nonlinearity, temperature dependences, among others) and model errors (cloud parameters, gas parameters, among others). Also, we should validate the whole procudure with real data and simulataneous measurements from the ground or other missions.

\section{Conclusions}

A procedure to determine the source and the representative altitude of the contrast seen in infrared images has been carried out. We show that the source of the small contrast expected in the $0.90-\mu \mathrm{m}$ image is mostly caused by inhomogeneity in cloud optical thickness. We also show that the source of the large contrast expected in the 2.26$\mu \mathrm{m}$ nightside image is also caused by inhomogeneity in the cloud optical thickness. Our attempt to determine the representative altitudes of these cloud layers revealed that this spectral band is sensitive to any cloud region (upper, middle and lower), but not sensitive to the upper haze region. This result is not always consistent with results reported by other researchers (e.g., Belton et al., 1991; Carlson et al., 1991). Cloud altitude deviation determined from the 2.02$\mu \mathrm{m}$ brightness may be affected by inhomogeneity in the cloud optical thickness. The temperature deviation determined from the $10-\mu \mathrm{m}$ brightness was found to be affected by the deviations in cloud optical thickness and cloud altitude. Cloud optical thickness, cloud altitude, and temperature information may be determined separately by introducing information obtained from other wavelength regions. Future studies should consider acidity as a parameter in addition to cloud thickness, height, and temperature, as indicated by Tsang et al. (2010).

Acknowledgments. The authors thank the OpenCLASTER project for the usage of the RSTAR (system for transfer of atmospheric radiation) package in this research. The authors also thank Dr. G. L. Hashimoto for modifying the RSTAR code for Venus. The authors also thank the two referees, Drs. C. C. C. Tsang and N. I. Ignatiev, for their constructive comments.

\section{References}

Belton, M. J. S., P. J. Gierasch, M. D. Smith, P. Helfenstein, P. J. Schinder, J. B. Pollack, K. A. Klaasen, J. Veverka, C. D. Anger, M. H. Carr, C. R. Chapman, M. E. Davies, F. P. Fanale, R. Greeley, R. Greenberg, J. W. Head III, D. Morrison, G. Neukum, and J. B. Pilcher, Images from Galileo of the Venus cloud deck, Science, 253, 1531-1536, 1991.

Carlson, R. W., K. H. Baines, T. Encrenaz, F. W. Taylar, P. Drossart, L. W. Kamp, J. B. Pollack, E. Lellouch, A. D. Collard, S. B. Calcutt, D. Grinspoon, P. R. Weissman, W. D. Smythe, A. C. Ocampo, G. E. Danielson, F. P. Fanale, T. V. Johnson, H. H. Kieffer, D. L. Matson, T. B. McCord, and L. A. Soderblom, Galileo infrared imaging spectroscopy mesurements at Venus, Science, 253, 1541-1548, 1991.

Crisp, D., Radiative forcing of the Venus mesosphere. I. Solar fluxes and heating rates, Icarus, 67, 484-514, 1986.

Gierasch, P. J., Meridional circulation and the maintenance of the Venus atmospheric rotation, J. Atmos. Sci., 32, 1038-1044, 1975.

Humlicek, J., Optimized computation of the Voigt and complex probability 
functions, J. Quant. Spectrosc. Radiat. Transfer, 27, 437-444, 1992.

Ignatiev, N. I., D. V. Titov, G. Piccioni, P. Drossart, W. J. Markiewicz, V. Cottini, Th. Roatsch, M. Almeida, and N. Manoel, Altimetry of the Venus cloud tops from the Venus Express observations, J. Geophys. Res., 114, E00B43, 2009.

Iwagami, N., S. Ohtsuki, K. Tokuda, N. Ohira, Y. Kasaba, T. Imamura, H. Sagawa, G. L. Hashimoto, S. Takeuchi, M. Ueno, and S. Okumura, Hemispheric distributions of $\mathrm{HCl}$ above and below the Venus' clouds by ground-based $1.7 \mu \mathrm{m}$ spectroscopy, Planet. Space Sci., 56, 1424-1434, 2008.

Iwagami, N., S. Takagi, S. Ohtsuki, M. Ueno, K. Uemizu, T. Satoh, T. Sakanoi, and G. L. Hashimoto, Science requirements and description of the $1 \mu \mathrm{m}$ camera onboard the Akatsuki Venus Orbiter, Earth Planets Space, 2011 (in press).

James, E. P., O. B. Toon, and G. Schubert, A numerical microphysical model of the condensational Venus cloud, Icarus, 129, 147-171, 1997.

Kawabata, K., D. L. Coffen, J. E. Hansen, W. A. Lane, M. Sato, and L. D. Travis, Cloud and haze properties from Pioneer Venus polarimetry, $J$. Geophys. Res., 85, 8129-8140, 1980.

Keating, G. M., J. L. Bertaux, S. W. Bougher, T. E. Cravens, R. E. Dickinson, V. A. Krasnopolsky, A. F. Nagy, J. Y. Nicholson III, L. J. Paxton, and U. von Zahn, Structure and composition, Venus International Reference Atmosphere IV, Adv. Space. Res., 5, 117-172, 1985.

Knollenberg, R. G. and D. M. Hunten, The microphysics of the clouds of the Pioneer Venus particle size spectrometer experiment, J. Geophys. Res., 85, 8039-8058, 1980.

Livingston, W. and L. Wallace, An atlas of solar spectrum in the infrared from 1850 to $9000 \mathrm{~cm}^{-1}$ (1.1-5.4 $\left.\mu \mathrm{m}\right)$, N.S.O. Technical Report \#91001, National Solar Observatory, National Optical Astronomy Observatories, P.O. Box 26732, Tucson, AZ 85726, USA, 1991.

Nakajima, T. and M. Tanaka, Matrix formulation for the transfer of solar radiation in a plane-parallel scattering atmosphere, J. Quant. Spectrosc. Radiat. Transfer, 35, 13-21, 1986.

Nakamura, M., T. Imamura, M. Ueno, N. Iwagami, T. Satoh, S. Watanabe, M. Taguchi, Y. Takahashi, M. Suzuki, T. Abe, G. Hashimoto, T. Sakanoi,
S. Okano, Y. Kasaba, J. Yoshida, M. Yamada, N. Ishii, T. Yamada, K. Uemizu, Y. Fukuhara, and K. Oyama, Planet-C: Venus Climate Orbiter mission of Japan, Planet. Space Sci., 55, 1831-1842, 2007.

Pollack, J. B., B. Dalton, D. Grinspoon, R. B. Wattson, R. Freedman, D. Crisp, A. Allen, B. Bezard, C. DeBergh, L. P. Giver, Q. Ma, and R. Tipping, Near-infrared light from Venus' nightside: A spectroscopic analysis, Icarus, 103, 1-42, 1993.

Rothman, L. S., D. Jacquemart, A. Barbe, D. C. Benner, M. Birk, L. R. Brown, M. R. Carleer, C. Chackerian, K. Chance, L. H. Coudert, V. Dana, V. M. Devi, J. M. Flaud, R. R. Gamache, A. Goldman, J. M. Hartmann, K. W. Jucks, A. G. Maki, J. Y. Mandin, S. T. Massei, J. Orphal, A. Perrin, C. P. Rinsland, M. A. H. Tochenov, R. A. Toth, J. V. Auwera, P. Varanasi, and G. Wagner, The HITRAN 2004 molecular spectroscopic database, J. Quant. Spectrosc. Radiat. Transfer, 96, 139204, 2005.

Schubert, G., General Circulation and the Dynamical State of the Venus Atmosphere, in Venus, pp. 681-765, Univ. of Arizona Press, 1983.

Tsang, C. C. C., F. W. Taylor, C. F. Wilson, S. J. Liddell, P. G. J. Irwin, G. Piccioni, P. Drossart, and S. B. Calcutt, Variability of CO concentrations in the Venus troposphere from Venus Express/VIRTIS using a band ratio technique, Icarus, 201, 432-443, 2009.

Tsang, C. C. C., C. F. Wilson, J. K. Barstow, P. G. J. Irwin, F. W. Taylor, K. McGouldrick, G. Piccioni, and P. Drossart, Correlations between cloud thickness and sub-cloud water abundance on Venus, Geophys. Res. Lett., 37, L02202, 2010.

Wattson, R. B. and L. S. Rothman, Direct numerical diagonalizationwave of the future, J. Quant. Spectrosc. Radiat. Transfer, 48(5-6), 763-780, 1992.

WCP-55, World Climate Research report of the experts meeting on aerosols and their climatic effects, edited by A. Deepak and H. E. Gerber, 107 pp, Williamsburg, Virginia, 28-30 March 1983, 1983.

S. Takagi (e-mail: seiko@eps.s.u-tokyo.ac.jp) and N. Iwagami 